\title{
Analisis Konsumsi Bahan Bakar Dump Truck Nissan UD CWM 330 Pada Penambangan Batubara di PT. Nan Riang
}

\author{
Adree Octova ${ }^{1^{*}}$ dan Raka Tubagus Indra Ramadhan ${ }^{1}$ \\ ${ }^{1}$ Jurusan Teknik Pertambangan, Fakultas Teknik, Universitas Negeri Padang \\ *Corresponding author, e-mail: adree@ft.unp.ac.id
}

\begin{abstract}
Abstrak - Aktifitas penambangan batubara di PT. Nan Riang menggunakan sistem tambang terbuka yang menargetkan produksi sebesar 1000 ton/hari. Penggunaan bahan bakar solar merupakan salah satu penyumbang biaya operasional yang cukup besar. Unit yang beroperasi untuk pengangkutan produksi yaitu lima unit dump truck Nissan UD CWM 330. Evaluasi yang ditargetkan yaitu mengetahui rasio penggunaan bahan bakar (liter) dengan produksi batubara (tonase). Ada beberapa faktor yang mempengaruhi konsumsi bahan bakar. Beberapa diantaranya yaitu kemiringan jalan angkut, RPM alat angkut, kecepatan alat angkut, rimpull alat angkut, jarak tempuh alat angkut, dan waktu tempuh alat angkut. Metode ini memanfaatkan analisis multivariat yang bertujuan untuk mendapatkan pengaruh dan mengukur intensitas hubungan antara variabel bebas dengan variabel terikat. 3. Bahan bakar aktual yang dihabiskan oleh keseluruhan alat angkut dump truck UD CWM 330 sebesar 1.589,52 liter/hari (5 dump truck). Bahan bakar yang dihabiskan oleh keseluruhan alat angkut dump truck UD CWM 330 setelah dilakukan perbaikan sebesar 1.206,27 liter/hari (6 dump truck).
\end{abstract}

Kata Kunci : Konsumsi Bahan Bakar, Biaya Bahan Bakar, Produktifitas

\begin{abstract}
Coal mining activities at PT. Nan Riang uses an open pit mining system that targets production of 1000 tons/day. The use of diesel fuel is a significant contributor to operational costs. The unit operating for production is five units of Nissan UD CWM 330 dump trucks. The targeted evaluation is knowing the ratio of fuel use (liters) to coal production (tonnage). There are several factors that affect fuel consumption. Some of them are the slope of the haul road, the RPM of the vehicle, the speed of the hauling tool, the rimpull of the conveyance, the distance of the hauling tool, and the travel time of the conveyance. This method utilizes multivaria $t$ analysis which aims to obtain influence and measure the intensity of the relationship between the independent variable and the dependent variable. The actual fuel spent by the entire UD CWM 330 dump truck was 1589.52 liters per day (for 5 dump trucks). The fuel spent by the entire UD CWM 330 dump truck after being repaired was 1206.27 liters per day (for 6 dump trucks).
\end{abstract}

Keywords : Fuel Consumption, Fuel Costs, Productivity

This is an open access article distributed under the Creative Commons 4.0 Attribution License

\section{Pendahuluan}

Salah satu perusahaan yang bergerak dibidang pertambangan batubara dengan metode tambang terbuka yaitu PT. Nan Riang. Alat berat yang digunakan untuk proses pemuatan yaitu excavator Komatsu PC 400, sedangkan alat angkut yang digunakan adalah dump truck Nissan UD CWM 330 untuk mengangkut material batubara dari front penambangan ke stockpile.

Penggunaan alat angkut sebagai peralatan utama dalam kegiatan operasional penambangan tidak dapat berjalan tanpa bahan bakar. Bahan bakar merupakan salah satu faktor yang perlu diperhatikan karena terdapat kecenderungan peningkatan harga bahan bakar yang akan mempengaruhi biaya produksi.

Penggunaan bahan bakar solar merupakan salah satu penyumbang biaya operasional penambangan yang paling besar sekitar $\pm 60 \%$.[3]

Salah satu faktor yang mempengaruhi konsumsi bahan bakar dan produksi yaitu kemiringan jalan. PT. Nan Riang telah menetapkan standar 
kemiringan jalan angkut yaitu $\leq 10 \%$. Namun berdasarkan hasil penelitian terdapat kemiringan melebihi standar target yang telah ditentukan yaitu $15,83 \%$ yang menyebabkan pemakaian bahan bakar \pm 150 liter/hari untuk satu unit alat angkut, serta mempengaruhi nilai RPM, kecepatan, dan rimpull. Dengan adanya beberapa faktor tersebut, analisis terhadap faktor - faktor yang berpengaruh terhadap konsumsi bahan bakar sangat diperlukan. Sehingga nantinya akan diketahui kondisi efektif atau ideal untuk pemakaian bahan bakar (fuel) minimum ketika alat angkut sedang bermuatan dan ketika alat angkut kosong.

Metode yang digunakan yaitu analisis multivariat dimana analisis multivariat dapat menghitung dan menganalisis lebih dari dua variabel bersamaan. Dapat mengetahui indikator pembentuk suatu variabel, menguji validitas dan reliabilitas suatu instrumen, mengkonfirmasi ketepatan model dan menguji pengaruh suatu variabel terhadap variabel lain. Memungkinkan peneliti untuk menyelidiki hubungan antara kategori variabel Dapat mengidentifikasi kelompok - kelompok variabel yang anggotanya memiliki kesamaan. Dapat membuat ringkasan informasi yang meringkas jumlah variabel yang banyak menjadi sejumlah faktor yang lebih sedikit (reduksi data).

Analisis Multivariat merupakan salah satu jenis analisis statistik yang digunakan untuk menganalisis data dimana data yang digunakan berupa banyak peubah bebas (independent variabel) dan juga peubah terikat (dependent variabel). Pada analisis ini bentuk hubungannya adalah beberapa variabel bebas terhadap satu variabel terikat. Analisis multivariat juga merupakan analisis multivariabel dalam satu atau lebih hubungan, analisis ini berhubungan dengan semua teknik statistik yang secara simultan menganalisis sejumlah pengukuran suatu objek. Analisis multivariat dapat didefinisikan secara sederhana sebagai metode pengolahan variabel dalam jumlah banyak untuk mencari pengaruhnya

\section{A. Regresi Linier Sederhana}

Regresi sederhana didasarkan pada hubungan fungsional ataupun kausal satu variabel independent dengan satu variabel dependent.

Persamaan umum regresi linier sederhana adalah:

$\mathrm{Y}=\mathrm{A}+\mathrm{bX}$

Dimana:

$\mathrm{Y}=$ Subyek dalam variabel dependen yang diprediksikan.

$\mathrm{A}=$ Harga $\mathrm{Y}$ ketika harga $\mathrm{X}=0$ (harga konstan). $\mathrm{b}=$ Angka arah atau koefisien regresi, yang menunjukkan angka peningkatan ataupun penurunan variabel dependent yang didasarkan pada perubahan variabel independent. Bila $(+)$ arah garis naik, dan bila (-) maka arah garis turun.

$\mathrm{X}=$ Subyek pada variabel indenpenden yang mempunyai nilai tertentu.[2][3][4]

Selain itu harga a dan $b$ dapat dicari dengan rumus berikut:

$\mathrm{a}=\frac{(\in Y)\left(\in X 1^{2}\right)-(\in X 1)(\in X 1 Y)}{n \in X 1^{2}-(\in X 1)^{2}}$
$\mathrm{~b}=\frac{n(\in X 1 Y)-(\in X 1)(\in Y)}{n \in X 1^{2}-(\in X 1)^{2}} \ldots \ldots$

\section{B. Regresi Linier Berganda}

Regresi linier berganda hampir sama dengan regresi linier sederhana, hanya saja pada regresi linier berganda variabel bebasnya lebih dari satu variabel penduga. Tujuan analisis regresi linier berganda adalah untuk mengukur intensitas hubungan antara dua atau lebih dan membuat prediksi perkiraan nilai $\mathrm{Y}$ atas $\mathrm{X}$.

Regresi linier berganda juga merupakan regresi dimana variabel terikatnya (Y) dihubungkan / dijelaskan lebih dari satu variabel, mungkin dua, tiga, dan seterusnya variabel bebas $(X 1, X 2, X 3, \ldots$, $X n$ ) namun masih menunjukan hubungan yang linear.

Regresi linear berganda berguna untuk mendapatkan pengaruh dua variabel kriteriummnya (bebas) atau untuk mencari hubungan fungsional dua variabel prediktor atau lebih dengan variabel kriteriumnya, atau untuk meramalkan dua variabel prediktor atau lebih terhadap variabel kriteriumnya.

Penambahan variabel bebas ini diharapkan dapat lebih menjelaskan karakteristik hubungan yang ada walaupun masih saja ada variabel yang terabaikan. Dalam regresi linier berganda variabel tak bebas (Y) tergantung kepada dua atau lebih variabel bebas (X).[1][9][13]

Persamaan garis regresi ganda untuk empat prediktor adalah:

$\mathrm{Y}=\mathrm{a}+b 1 \times 1+b 2 \times 2+b 3 \times 3+b 4 \times 4$

Dimana:

$\mathrm{Y}=$ variabel terikat

$\mathrm{x}=$ variabel-variabel bebas

$\mathrm{a}=$ konstanta (intercept)

$\mathrm{b}=$ koefisien regresi pada masing-masing variabel bebas.

Untuk bisa membuat persamaan melalui regresi, maka data setiap variabel harus tersedia. Selanjutnya berdasarkan data itu peneliti harus dapat menemukan persamaan melalui perhitungan. 
Untuk menghitung harga - harga a, $b 1, b 2, b 3$, dan $b 4$ dapat menggunakan persamaan berikut:

$\Sigma X_{1} Y=b_{1} \Sigma x_{1^{2}}+b_{2} \Sigma X_{1} X_{2}+b_{3} \Sigma X_{1} X_{3}+b_{4} \Sigma X_{1}$

$X_{4}$

$\Sigma X_{2} Y=b_{1} \Sigma X_{1} X_{2}+b_{2} \Sigma x_{2^{2}}+b_{3} \Sigma X_{2} X_{3}+b_{4} \Sigma X_{2}$

$X_{4}$

$\Sigma X_{3} Y=b_{1} \Sigma X_{1} X_{3}+b_{2} \Sigma X_{2} X_{3}+b_{3} \Sigma X_{3^{2}}+b_{4} \Sigma X_{3}$

$X_{4}$

$\Sigma X_{4} Y=b_{1} \Sigma X_{1} X_{4}+b_{2} \Sigma X_{2} X_{4}+b_{3} \Sigma X_{3} X_{4}+b_{4}$

$\Sigma X_{4^{2}}$

$\mathrm{a}=\bar{Y}-b_{1} \bar{X}_{1}-b_{2} \bar{X}_{2}-b_{3} \bar{X}^{3}-b_{4} \bar{X}_{4}$

Koefisien determinasi dinyatakan dengan $R^{2}$ untuk pengujian regresi linear berganda yang mencakup lebih dari dua variabel.

Alat angkut adalah alat yang digunakan untuk memindahkan material hasil penambangan ke tempat penimbunan atau pengolahan. Pengangkutan batuan, endapan bijih, dan lain - lain merupakan suatu hal yang sangat mempengaruhi operasi produksi penambangan. Untung rugi suatu perusahaan tambang terletak juga pada lancar tidaknya pengangkutan yang tersedia. Untuk produktifitas alat angkut (dump truck) dapat dihitung menggunakan rumus berikut:

$\mathrm{Q}=\frac{C \times 60 \times E f f}{C m t} \times \mathrm{Sf} \operatorname{dimana} \mathrm{C}=\mathrm{n} \times \mathrm{q} \times \mathrm{K} \ldots \ldots$

Dimana:

$\mathrm{Q}=$ Produksi per jam

$\mathrm{C} \quad=$ Kapasitas produksi per siklus dump truck

$\mathrm{n} \quad=$ Jumlah dump truck

$\mathrm{q}=$ Kapasitas produksi per siklus excavator

Cmt $=$ Waktu siklus dump truck

Eff $=$ Efisiensi Kerja

$\mathrm{K}=$ Faktor pengisian bucket

$\mathrm{Sf}=$ Swell Factor

\section{Metode Penelitian}

Analisis statistik multivariat memungkinkan untuk melakukan penelitian terhadap lebih dari dua variabel secara bersamaan dan digunakan untuk megetahui apakah rata - rata kelompok berbeda secara signifikan, dimana variabel dependennya bertipe metrik dan variabel independennya bertipe nonmetrik. Yang termasuk kedalam analisis multivariat adalah analisis regresi linear berganda.

Regresi linier berganda merupakan regresi yang variabel terikatnya $(\mathrm{Y})$ dihubungkan/dijelaskan lebih dari suatu variabel bebas $(\mathrm{x} 1, \mathrm{x} 2, \mathrm{x} 3, \ldots, \mathrm{xn})$ namun masih menunjukan diagram hubungan yang linear.
Penambahan variabel bebas ini diharapkan dapat lebih menjelaskan karakteristik hubungan yang ada walaupun masih saja ada variabel yang terabaikan.

Penelitian dilakukan dengan menggunakan metode analisis multivariat dengan objek dump truck UD CWM 330 ketika bermuatan dan ketika kosong dengan mengamati nilai-nilai dari kemiringan jalan, RPM, kecepatan, rimpull, jarak tempuh, waktu tempuh, dan bahan bakar. Sehingga didapatkan suatu hubungan penggunaan konsumsi bahan bakar dump truck UD CWM 330.

\section{HASIL DAN PEMBahasaN}

\section{A. Pengaruh Konsumsi Bahan Bakar}

Penggunaan konsumsi bahan bakar pada alat angkut merupakan salah satu hal yang perlu diperhatikan oleh pihak perusahaan dimana penggunaan bahan bakar merupakan salah satu penyumbang biaya operasional yang cukup besar. Faktor - faktor yang mempengaruhi penggunaan bahan bakar pada alat angkut mesti sangat diperhatikan.

\section{Geometri Jalan}

Pada lokasi Pit Jebak pemuatan dan pengangkutan material batubara menggunakan alat muat jenis excavator Komatsu PC 400 dan alat angkut dump truck Nissan UD CWM 330. Layout dan penampang jalan dapat dilihat pada Gambar 1 dan Gambar 2.

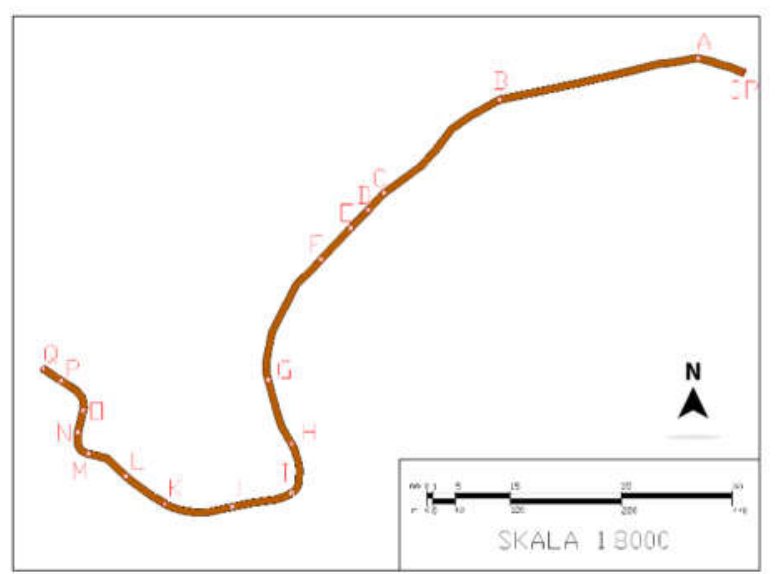

Gambar 1. Layout Jalan Produksi Pit Jebak PT. Nan Riang 


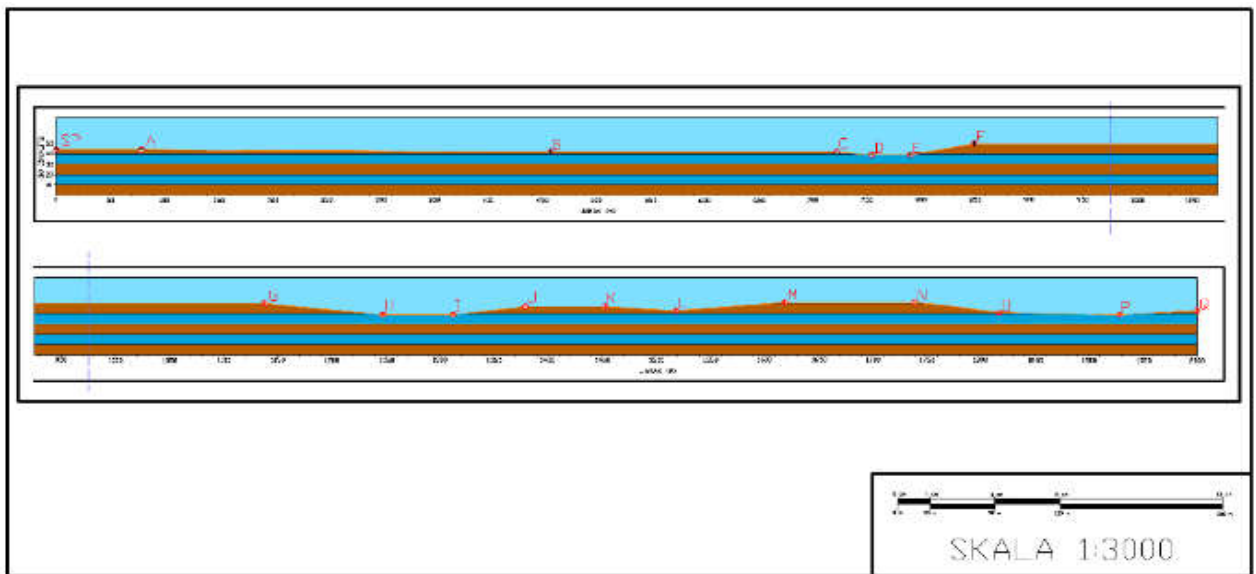

Gambar 2. Penampang Jalan Produksi Pit Jebak PT. Nan Riang

\section{Lebar Jalan}

Lebar jalan produksi (dalam keadaan lurus dan tikungan dimulai dari stockpile) pada daerah PT. Nan Riang pada jalur bermuatan dan kosong seperti pada Tabel 1.[5][7]

Tabel 1. Lebar Jalan Produksi Lurus dan Tikungan

\begin{tabular}{|c|c|c|}
\hline \multirow{2}{*}{ Panjang Jalan (m) } & \multicolumn{2}{|c|}{ Lebar (m) } \\
\cline { 2 - 3 } & Lurus & Tikungan \\
\hline 79.04 & 7.3 & \\
\hline 56.03 & & 8.8 \\
\hline 322.21 & 9.4 & \\
\hline 113.74 & & 10.3 \\
\hline 48.41 & 7.5 & \\
\hline 102.94 & & 10.5 \\
\hline 318.18 & 6.7 & \\
\hline 97.16 & & 9.2 \\
\hline 131.68 & 7.1 & \\
\hline 147.3 & & 7.96 \\
\hline 101.35 & 6.8 & \\
\hline 100.84 & & 6.6 \\
\hline 119.63 & 6.6 & \\
\hline 30.87 & & 5 \\
\hline 86.88 & & 9.3 \\
\hline 27.89 & 9 & \\
\hline 44.4 & & 7.15 \\
\hline 64.22 & 6.8 & \\
\hline 1992.77 & & Jumlah \\
\hline
\end{tabular}

\section{Kemiringan Jalan Produksi}

Kemiringan jalan produksi berhubungan langsung dengan kemampuan alat angkut baik dalam pengereman maupun dalam mengatasi tanjakan. Kemiringan jalan umumnya dinyatakan dalam persen (\%).[8]

\section{Kemiringan Melintang (cross slope)}

Kemiringan melintang adalah beda tinggi antara titik tengah jalan dengan sisi - sisi pinggir jalan. Kemiringan melintang digunakan untuk mengatasi masalah drainase diatas permukaan jalan. Secara umum jalan produksi yang menghubungkan stockpile menuju Pit Jebak memiliki angka kemiringan melintang berkisar antara $0-52 \mathrm{~mm} / \mathrm{m}$ terbagi dibeberapa segmen. Selain itu ditemukan juga ruas jalan yang tidak memiliki cross slope. Menurut Awang Suwandi (2004:13), jalan produksi yang baik memiliki kemiringan melintang $20 \mathrm{~mm} / \mathrm{m}$ sampai $40 \mathrm{~mm} / \mathrm{m}$.[10]

\section{Superelevasi}

Superelevasi adalah kemiringan badan jalan pada tikungan. Superelevasi ini bertujuan untuk membantu kendaraan dalam mengatasi tikungan. Dengan superelevasi yang ada, diharapkan alat angkut tidak tergelincir pada saat melewati tikungan dengan kecepatan yang maksimum. Secara umum superelevasi yang ada di PT. Nan Riang berkisar antara $0-52 \mathrm{~mm} / \mathrm{m}$, namun terdapat juga segmen yang tidak memiliki superelevasi. Sehingga ketika alat angkut melewati tikungan kecepatan yang dipakai sangat rendah sehingga berpengaruh pada cycle time pada alat angkut semakin besar. [14]

\section{Karakteristik Jalur Angkut Material}

Karakteristik permukaan jalan, jarak tempuh, dan kemiringan jalan yang berbeda - beda dapat mempengaruhi tingkat produktifitas alat yang digunakan dan juga mempengaruhi konsumsi bahan bakar alat tersebut. Salah satu asumsi yang digunakan dalam menentukan parameter tahanan gulir (rolling resistance) adalah setiap jalur memiliki tahanan gulir yang sama sebesar 100 lbs/ton karena jenis material yang sama.[6][8]

\section{Tahanan Kemiringan}

Perhitungan tahanan kemiringan yang dilakukan pada penelitian ini adalah dengan cara menghitung kemiringan jalan per segmen jalan. Peta situasi jalan yang diamati, lalu dibuat penampang melintang (cross section) dari jalan 
tersebut, kemudian dihitung kemiringan jalan setiap segmen. Jalur produksi memiliki jarak tempuh 1992.77 meter dengan kemiringan jalan maksimum $15.83 \%$ ketika kosong dan $14.05 \%$ ketika bermuatan. Kemiringan jalan dihitung dengan membagi jalan menjadi beberapa segmen berdasarkan data pengambilan di lapangan.[8]

B. Data Kemiringan Jalan, RPM, Kecepatan, Rimpull, Jarak Tempuh dan Waktu Tempuh Terhadap Bahan Bakar

Tabel 2. Data Kemiringan Jalan, RPM, Kecepatan, Rimpull, Jarak Tempuh, Waktu Tempuh, dan Bahan Bakar UD CWM 330 Ketika Kosong

\begin{tabular}{|c|c|c|c|c|c|c|c|}
\hline Begmen & Kemiringan Jalan (\%) & RPM & Kecepatan (km/h) & Rimpull (lbs) & Jarak Tempuh (m) & Waktu Tempuh (s) & Bahan Bakar (liter/jam) \\
\hline SP - A & 0 & 1120 & 23 & 7650.40 & 79.09 & 12.38 & 21.75 \\
\hline A - B & -3.49 & 1100 & 25 & 6374.76 & 378.24 & 54.47 & 21.43 \\
\hline B - C & 0 & 1120 & 23 & 7650.40 & 265.09 & 41.49 & 21.75 \\
\hline C - D & -8.74 & 1060 & 26 & 6215.37 & 32.26 & 4.47 & 20.78 \\
\hline D - E & 0 & 1120 & 23 & 7650.40 & 36.05 & 5.64 & 21.75 \\
\hline E - F & 15.83 & 1600 & 19 & 10201.67 & 59.11 & 11.20 & 29.55 \\
\hline F - G & 0 & 1120 & 23 & 7650.40 & 288.34 & 45.13 & 21.75 \\
\hline G - H & -10.51 & 1040 & 28 & 5896.59 & 109.12 & 14.03 & 20.45 \\
\hline H - I & 0 & 1120 & 23 & 7650.40 & 65.17 & 10.20 & 21.75 \\
\hline I - J & 12.27 & 1400 & 20 & 9563.85 & 67.08 & 12.07 & 26.30 \\
\hline J - K & 0 & 1120 & 23 & 7650.40 & 74.21 & 11.62 & 21.75 \\
\hline K - L & -8.74 & 1060 & 26 & 6215.37 & 65.01 & 9.00 & 20.78 \\
\hline L - M & 14.05 & 1520 & 21 & 8926.03 & 100.84 & 17.29 & 28.25 \\
\hline M - N & 0 & 1120 & 23 & 7650.40 & 119.63 & 18.72 & 21.75 \\
\hline N - O & -14.05 & 1000 & 30 & 5577.81 & 78.02 & 9.36 & 19.80 \\
\hline O - P & -3.49 & 1100 & 25 & 6374.76 & 111.29 & 16.03 & 21.43 \\
\hline P - Q & 6.99 & 1280 & 22 & 8288.21 & 64.22 & 10.51 & 24.35 \\
\hline
\end{tabular}

Tabel 3. Data Kemiringan Jalan, RPM, Kecepatan, Rimpull, Jarak Tempuh, Waktu Tempuh, dan Bahan Bakar UD CWM 330 Ketika Bermuatan

\begin{tabular}{|c|c|c|c|c|c|c|c|}
\hline Segmen & Kemiringan Jalan (\%) & RPM & $\operatorname{Kecepatan}(\mathrm{km} / \mathrm{h})$ & Rimpull (lbs) & Jarak Tempuh (m) & Waktu Tempuh (s) & Bahan Bakar (liter/jam) \\
\hline$P-Q$ & -6.99 & 1530 & 21 & 8926.03 & 64.22 & 11.01 & 28.38 \\
\hline $\mathrm{O}-\mathrm{P}$ & 3.49 & 1550 & 17 & 11477.30 & 111.29 & 23.57 & 28.70 \\
\hline $\mathrm{N}-\mathrm{O}$ & 14.05 & 2595 & 13 & 14028.58 & 78.02 & 21.61 & 45.42 \\
\hline $\mathrm{M}-\mathrm{N}$ & 0 & 1540 & 20 & 9563.85 & 119.63 & 21.53 & 28.54 \\
\hline $\mathrm{L}-\mathrm{M}$ & -14.05 & 1510 & 24 & 7012.58 & 100.84 & 15.13 & 28.06 \\
\hline $\mathrm{K}-\mathrm{L}$ & 8.74 & 2095 & 16 & 12115.12 & 65.01 & 14.63 & 37.42 \\
\hline $\mathrm{J}-\mathrm{K}$ & 0 & 1540 & 20 & 9563.85 & 74.21 & 13.36 & 28.54 \\
\hline $\mathrm{I}-\mathrm{J}$ & -12.27 & 1520 & 22 & 8288.21 & 67.08 & 10.98 & 28.22 \\
\hline $\mathrm{H}-\mathrm{I}$ & 0 & 1540 & 20 & 9563.85 & 65.17 & 11.73 & 28.54 \\
\hline $\mathrm{G}-\mathrm{H}$ & 10.51 & 2100 & 15 & 12752.94 & 109.12 & 26.19 & 37.50 \\
\hline$F-G$ & 0 & 1540 & 20 & 9563.85 & 288.34 & 51.90 & 28.54 \\
\hline$E-F$ & -15.83 & 1500 & 26 & 6215.37 & 59.11 & 8.18 & 27.90 \\
\hline $\mathrm{D}-\mathrm{E}$ & 0 & 1540 & 20 & 9563.85 & 36.05 & 6.49 & 28.54 \\
\hline$C-D$ & 8.74 & 2095 & 16 & 12115.12 & 32.26 & 7.26 & 37.42 \\
\hline$B-C$ & 0 & 1540 & 20 & 9563.85 & 265.09 & 47.72 & 28.54 \\
\hline$A-B$ & 3.49 & 1550 & 17 & 11477.30 & 378.24 & 80.10 & 28.70 \\
\hline SP - A & 0 & 1540 & 20 & 9563.85 & 79.09 & 14.24 & 28.54 \\
\hline
\end{tabular}

Dari data - data hasil penelitian didapatkan beberapa parameter seperti kemiringan jalan, RPM, kecepatan, rimpull, jarak tempuh, waktu tempuh, dan bahan bakar yang dibutuhkan oleh alat angkut saat melintasi jalan produksi dalam keadaan bermutan dan keadaan kosong seperti pada Tabel 2 dan Tabel 3. 


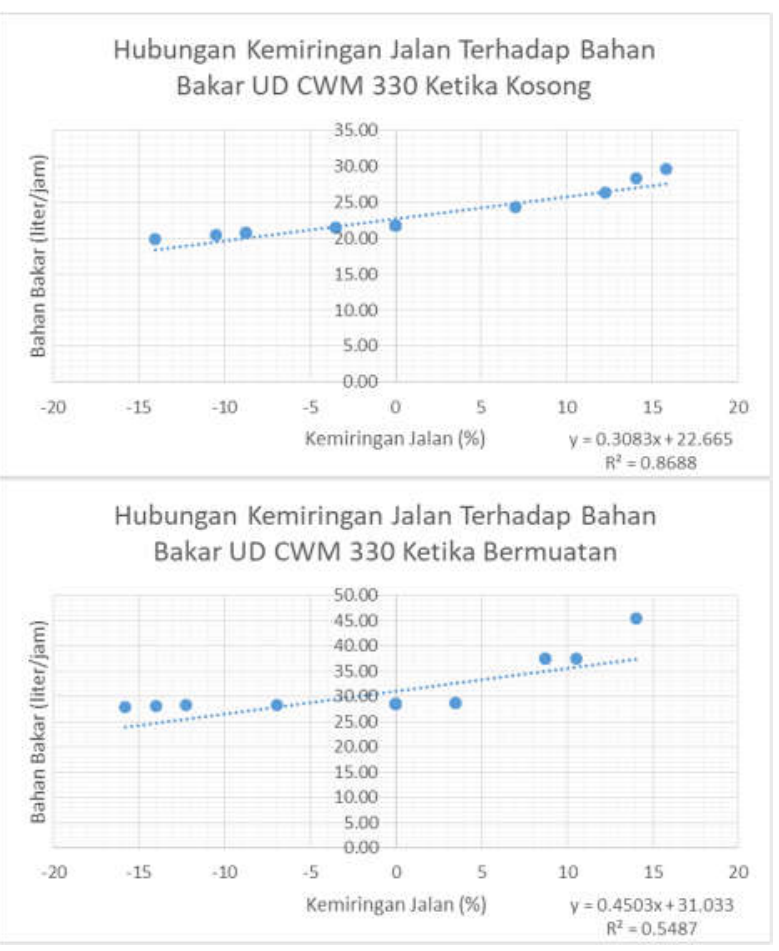

Gambar 3. Grafik Perbandingan Kemiringan Jalan terhadap Bahan Bakar UD CWM 330 Ketika Kosong dan Bermuatan

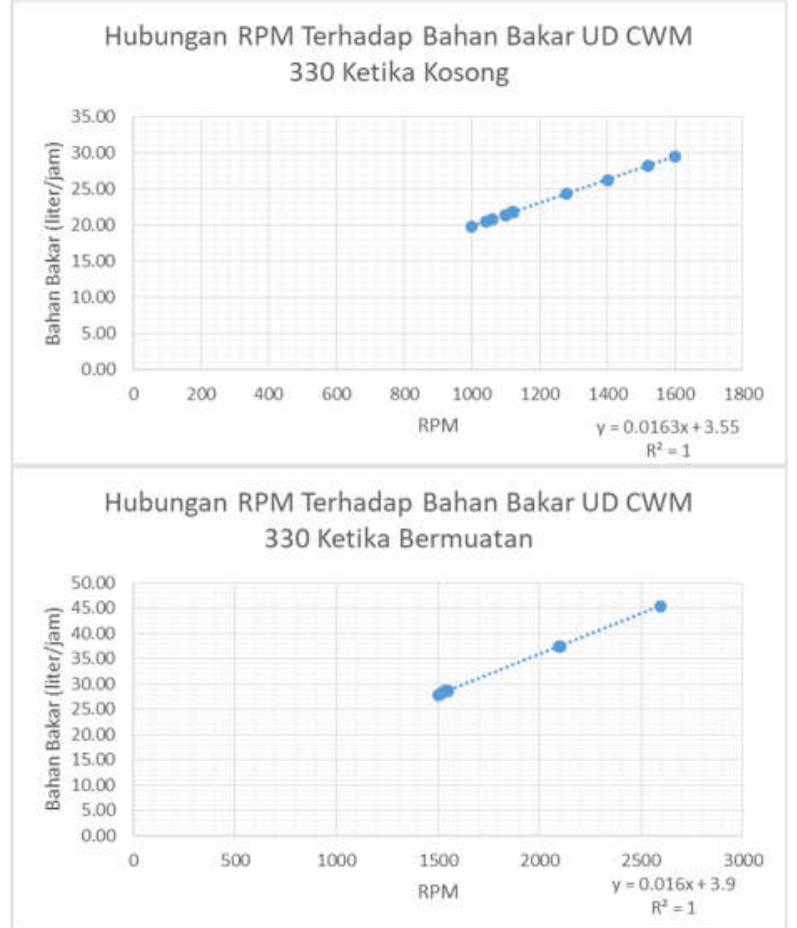

Gambar 4. Grafik Perbandingan RPM Terhadap Bahan Bakar UD CWM 330 Ketika Kosong dan Bermuatan

\section{Hubungan Kemiringan Jalan Terhadap Bahan Bakar}

Hubungan antara nilai kemiringan jalan dengan bahan bakar alat angkut UD CWM 330 dapat dilihat pada Gambar 3.

Dari Gambar 3 dapat dilihat bahwa seiring bertambahnya kemiringan jalan maka konsumsi bahan bakar juga akan meningkat sebesar 0.3083 liter/jam untuk keadaan kosong dan 0.4503 liter/jam untuk keadaan bermuatan

\section{Hubungan RPM (Rotasi Per Menit) Terhadap Bahan Bakar}

Hubungan antara nilai RPM dengan bahan bakar alat angkut UD CWM 330 dapat dilihat pada Gambar 4.

Dari Gambar 4 dapat dilihat bahwa seiring bertambahnya nilai RPM maka konsumsi bahan bakar juga akan meningkat sebesar 0.016 liter/jam untuk keadaan kosong dan 0.016 liter/jam untuk keadaan bermuatan

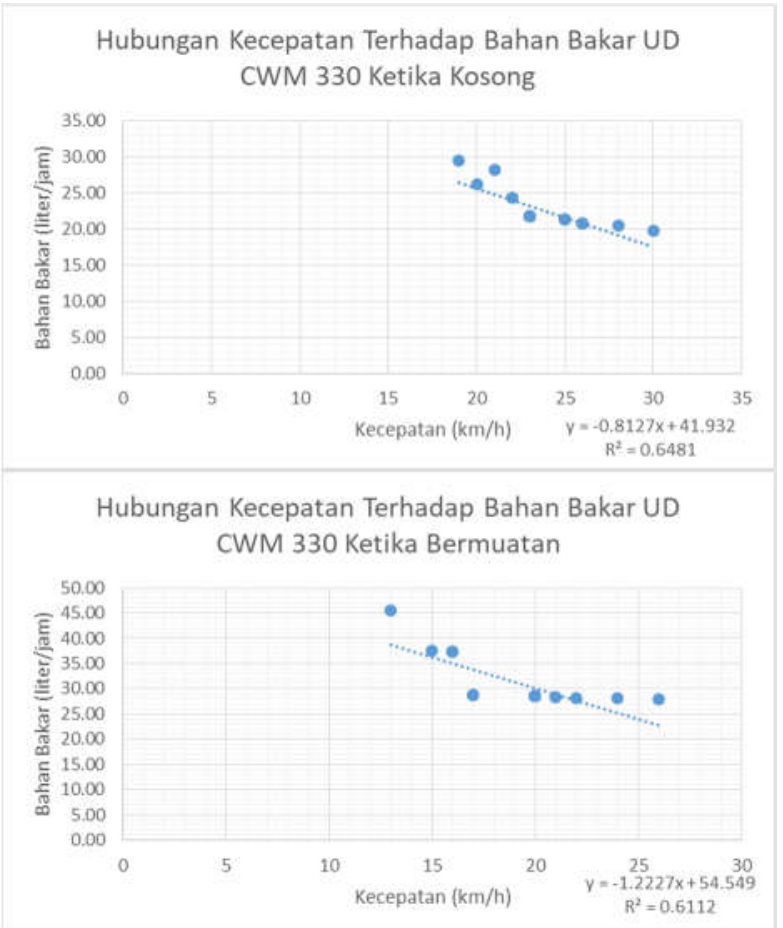

Gambar 5. Grafik Perbandingan Kecepatan Terhadap Bahan Bakar UD CWM 330 Ketika Kosong dan Bermuatan

\section{E. Hubungan Kecepatan Terhadap Bahan Bakar}

Hubungan antara nilai kecepatan dengan bahan bakar alat angkut UD CWM 330 dapat dilihat pada Gambar 5.

Dari Gambar 5 dapat dilihat bahwa seiring bertambahnya kecepatan maka konsumsi bahan bakar akan menurun sebesar 0.812 liter/jam untuk keadaan kosong dan 1.222 liter/jam untuk keadaan bermuatan 
Hubungan Rimpull Terhadap Bahan Bakar UD CWM 330 Ketika Kosong

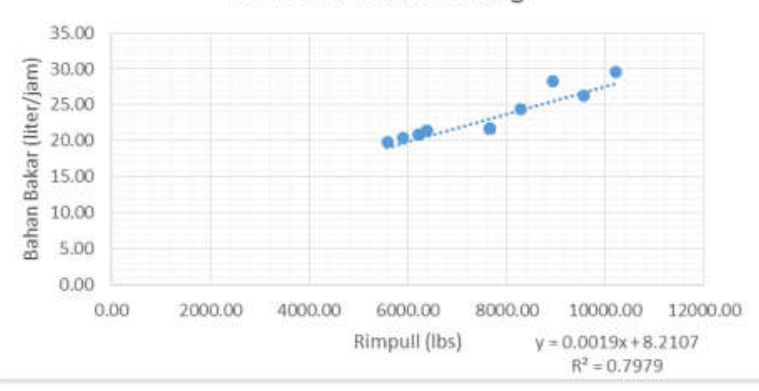

Hubungan Rimpull Terhadap Bahan Bakar UD CWM 330 Ketika Bermuatan

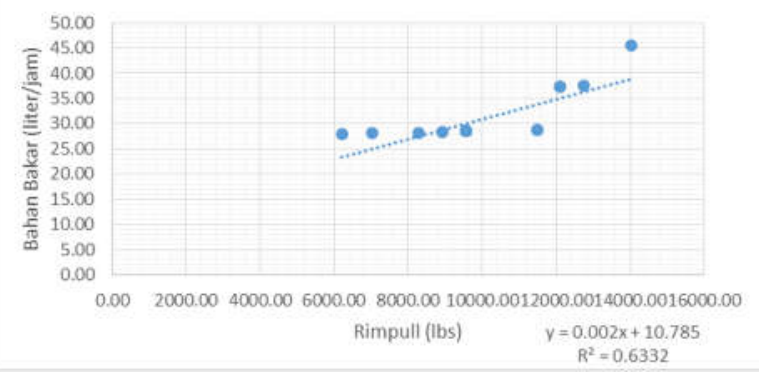

Gambar 6. Grafik Perbandingan Rimpull Terhadap Bahan Bakar UD CWM 330 Ketika Kosong dan Bermuatan

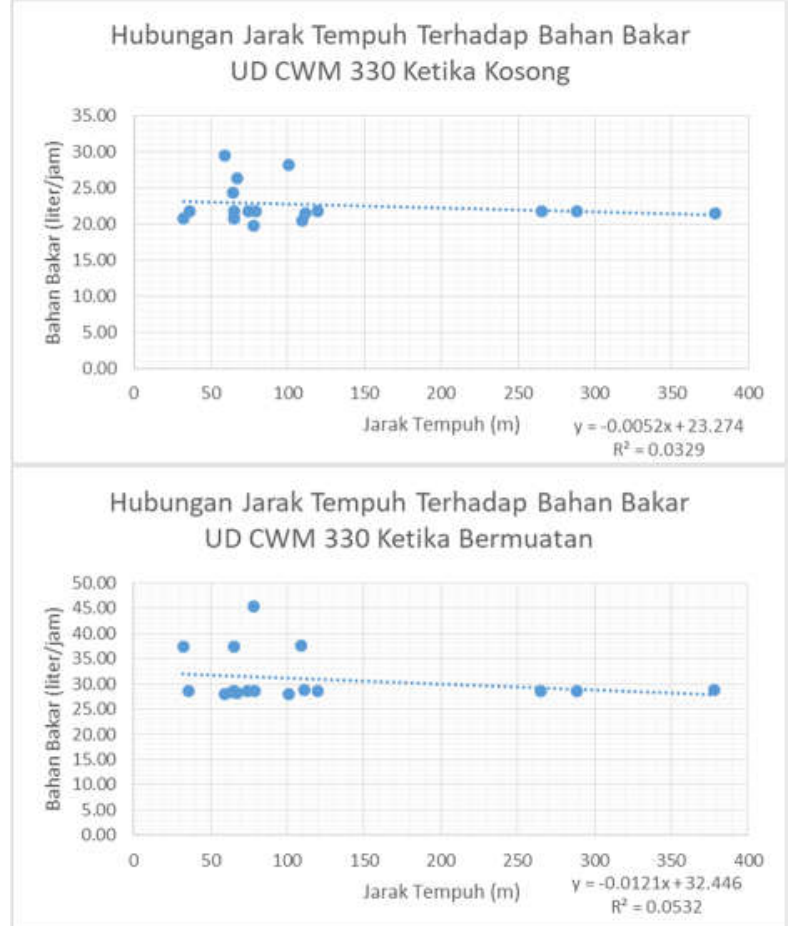

Gambar 7. Grafik Perbandingan Jarak Tempuh Terhadap Bahan Bakar UD CWM 330 Ketika Kosong dan Bermuatan

\section{F. Hubungan Rimpull Terhadap Bahan Bakar}

Hubungan antara nilai rimpull dengan bahan bakar alat angkut UD CWM 330 dapat dilihat pada Gambar 6. Dari Gambar 6 dapat dilihat bahwa seiring bertambahnya Rimpull maka konsumsi bahan bakar juga akan meningkat sebesar 0.0019 liter/jam untuk keadaan kosong dan 0.002 liter/jam untuk keadaan bermuatan

\section{G. Hubungan Jarak Tempuh Terhadap Bahan Bakar}

Hubungan antara nilai jarak tempuh dengan bahan bakar alat angkut UD CWM 330 dapat dilihat pada Gambar 7. Dari Gambar 7 dapat dilihat bahwa seiring bertambahnya jarak tempuh maka konsumsi bahan bakar juga akan menurun sebesar 0.005 liter/jam untuk keadaan kosong dan 0.0121 liter/jam untuk keadaan bermuatan

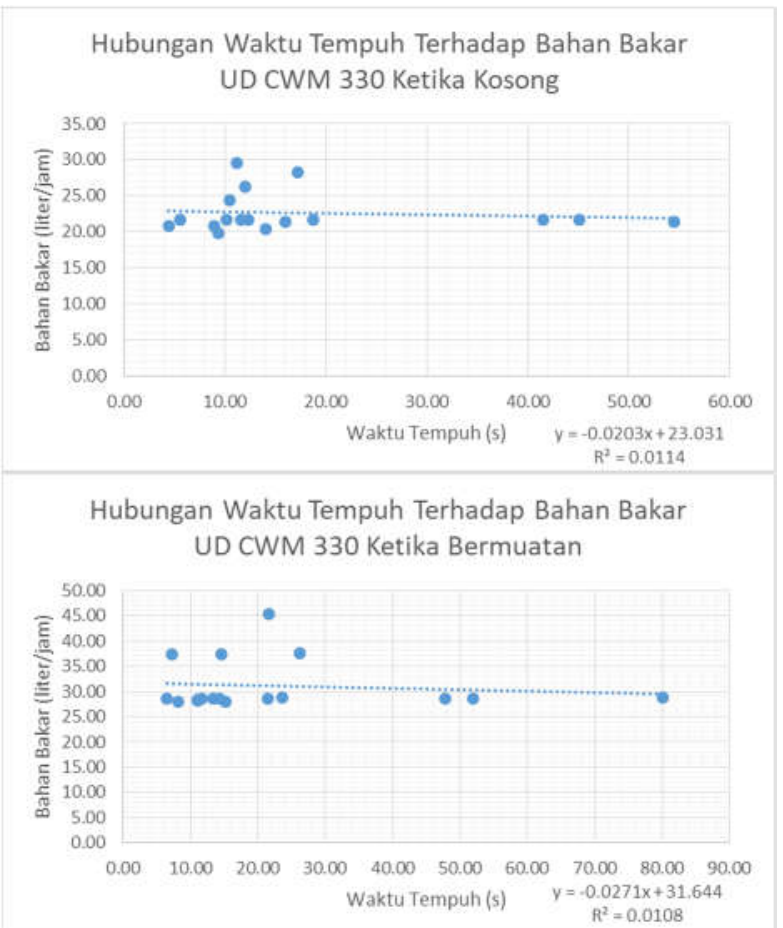

Gambar 8. Grafik Perbandingan Waktu Tempuh Terhadap Bahan Bakar UD CWM 330 Ketika Kosong dan Bermuatan

\section{H. Hubungan Waktu Tempuh Terhadap Bahan Bakar}

Hubungan antara waktu tempuh dengan bahan bakar alat angkut UD CWM 330 dapat dilihat pada Gambar 8.Dari Gambar 8 dapat dilihat bahwa seiring bertambahnya kemiringan jalan maka konsumsi bahan bakar juga akan menurun sebesar 0.0203 liter/jam untuk keadaan kosong dan 0.0221 liter/jam untuk keadaan bermuatan

\section{Pengaruh Kemiringan Jalan, RPM, Kecepatan, Rimpull, Jarak Tempuh dan Waktu Tempuh Terhadap Bahan Bakar}


Regresi linier berganda yaitu linier yang mempunyai minimal tiga buah variabel. Variabel variabel tersebut adalah dua variabel bebas (independent variabel) dan satu variabel terikat (dependent variabel). Dalam pembahasan ini variabel bebas adalah kemiringan jalan (X1), RPM (X2), kecepatan (X3), rimpull (X4), jarak tempuh (X5), dan waktu tempuh (X6), serta yang menjadi variabel terikat adalah bahan bakar (Y). Berdasarkan perhitungan regresi linier berganda dengan perhitungan menggunakan software IBM SPSS Statistics 23 didapatkan persamaan regresi: $\mathrm{Y}=-2,804+0,014 \mathrm{X} 1+0,002 \mathrm{X} 2-0,003 \mathrm{X} 3+$ $0,000006958 X 4-0,00002510 X 5-0,001 X 6$ untuk UD CWM 330 ketika kosong, dan $\mathrm{Y}=-3.091+$ $0,016 \mathrm{X} 1+0,003 \mathrm{X} 2-0,004 \mathrm{X} 3+0,000004695 \mathrm{X} 4-$ $0,00009665 X 5-0,001 \times 6$ untuk UD CWM 330 ketika bermuatan.

J. Perhitungan Produktifitas dan Biaya Bahan Bakar Alat Angkut UD CWM 330
Produktifitas Alat Angkut UD CWM 330

Produksi alat angkut UD CWM 330 aktual didapatkan berdasarkan pada pengamatan cycle time dilapangan dan dapat dilihat produksi batubara perhari dari 5 unit alat angkut UD CWM 330 rata - rata 636,34 ton/hari seperti pada Tabel 23. Sedangkan target produksi dari PT. Nan Riang sebesar 1000 ton/hari dengan harga periode September 2017 sebesar US\$92,03/ton atau Rp1.242.405,-/ton (US\$1 = Rp13.500,-).

\section{Biaya Bahan Bakar Alat Angkut UD CWM 330}

Dengan harga solar industri periode September 2017 sebesar Rp11.000,-/liter maka didapatkan estimasi income aktual perusahaan yang dapat dilihat pada Tabel 4. Untuk estimasi income perusahaan ini tidak berdasarkan dari cost yang lainnya tetapi hanya terbatas pada penjualan batubara dan pengeluaran pembelian bahan bakar dump truck UD CWM 330 saja.

Tabel 4. Estimasi Income Aktual

\begin{tabular}{|c|c|r|c|r|r|r|}
\hline \multicolumn{2}{|c|}{ Bahan Bakar } & $\begin{array}{c}\text { Biaya Bahan } \\
\text { Bakar (Rp) }\end{array}$ & \multicolumn{2}{c|}{ Produksi Batubara } & $\begin{array}{c}\text { Penjualan } \\
\text { Batubara (Rp) }\end{array}$ & Income (Rp) \\
\hline liter/jam & 53.70 & 590,700 & ton/jam & 21.12 & $26,239,594$ & $25,648,894$ \\
\hline liter/hari & 317.90 & $3,496,944$ & ton/hari & 127.27 & $158,120,884$ & $154,623,940$ \\
\hline liter/bulan & 9537.12 & $104,908,320$ & ton/bulan & 3818.10 & $4,743,626,531$ & $4,638,718,211$ \\
\hline 5 dump truck /jam & 268.50 & $2,953,500$ & 5 dump truck/jam & 105.59 & $131,185,544$ & $128,232,044$ \\
\hline 5 dump truck/hari & 1589.52 & $17,484,720$ & 5 dump truck/hari & 636.34 & $790,591,998$ & $773,107,278$ \\
\hline 5 dump truck/bulan & 47685.60 & $524,541,600$ & 5 dump truck/bulan & 19090.20 & $23,717,759,931$ & $23,193,218,331$ \\
\hline
\end{tabular}

\section{Diagram Fishbone}

Berdasarkan pengamatan dilapangan dapat dibuat diagram fishbone dari alat angkut UD CWM 330 dapat dilihat pada gambar 9 .

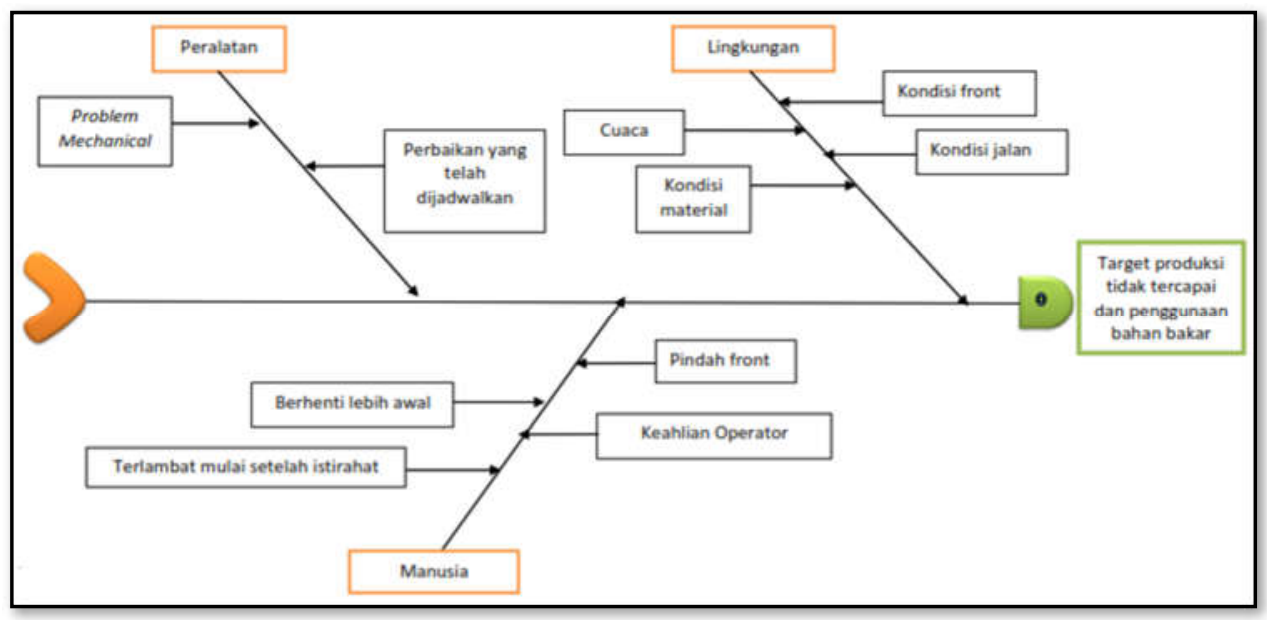

Gambar 9. Diagram Fishbone Dump Truck CWM 330 
K. Perhitungan Pencapaian Target Produksi 1000 ton/hari dan Estimasi Income Perusahaan

\section{Perbaikan Waktu Hambatan}

Perbaikan waktu hambatan dilakukan dengan penekanan terhadap waktu yang hilang (loss time) sehingga waktu kerja efektif bisa meningkat. Perbaikan yang dilakukan difokuskan pada waktu hambatan yang dapat dihindari. Perbaikan waktu hambatan bisa dilihat pada Tabel 5 .

Tabel 5. Perbaikan Waktu Hambatan

\begin{tabular}{|c|c|c|}
\hline Waktu Hambatan & Aktual (menit) & Perbaikan (menit) \\
\hline Waktu Tersedia & 529.80 & 529.80 \\
\hline Waktu Hambatan Yang Dapat Dihindari & & \\
\hline Terlambat Kerja & 27.30 & 10.00 \\
\hline Istirahat Sebelum Waktunya & 2.53 & 0.00 \\
\hline Terlambat Setelah Istirahat & 19.20 & 10.00 \\
\hline Berhenti Sebelum Akhir Kerja & 0.83 & 0.00 \\
\hline Pengisian Bahan Bakar Tiba - Tiba & 9.37 & 5.00 \\
\hline Jumlah & 59.23 & 25.00 \\
\hline Waktu Hambatan Yang Tidak Dapat Dihindari & & \\
\hline Istirahat & 100.00 & 100.00 \\
\hline Hujan & 16.60 & 16.60 \\
\hline Jumlah & 116.60 & 116.60 \\
\hline Waktu Kerja Efektif & 353.97 & 388.20 \\
\hline Waktu Kerja Efektif (jam) & 5.9 & 6.5 \\
\hline
\end{tabular}

Perbaikan waktu hambatan yang dilakukan dengan meminimalkan waktu terlambat memulai kerja dipagi hari, istirahat sebelum waktunya, terlambat setelah istirahat, dan berhenti sebelum akhir kerja dengan cara mengawasi dan mengontrol langsung kegiatan yang dilakukan pekerja pada saat di front penambangan maupun di stockpile, apabila perbaikan waktu hambat dapat dilakukan seperti perkiraan pada Tabel 5, maka jam kerja efektif akan meningkat sehingga dapat menaikan produksi.

\section{Perbaikan Jalan Produksi Berdasarkan Evaluasi Geometri Jalan dengan Ketentuan AASHTO \\ Lebar Jalan}

Segmen jalan produksi dari Pit Jebak menuju stockpile semuanya adalah jalur ganda. Lebar jalan pada keadaan lurus adalah jumlah jalur kali lebar truck ditambah setengah lebar truck untuk tepi kanan dan kiri serta ditambah setengah lebar truck untuk jarak antara dua truck yang saling berpapasan. Apabila menggunakan spesifikasi teknis dump truck terbesar di PT. Nan Riang yaitu ADT Volvo A40E yang memiliki lebar 3,4 meter, maka lebar jalan minimum untuk dua jalur pada jalan lurus adalah 12 meter. Lebar jalan lurus yang ada di PT. Nan Riang secara umum belum memenuhi standar yang ada. Maka dari itu harus dilakukan pelebaran jalan.

Lebar jalan pada saat kendaraan menikung (membelok) selalu lebih besar dari pada lebar jalan lurus. Untuk alat angkut yang menggunakan ADT Volvo A40E dengan lebar 3,4 meter, maka lebar jalan minimum pada tikungan adalah sebesar 21 meter untuk dua jalur. Sehingga ada beberapa segmen pada tikungan perlu dilakukan penambahan lebar jalan.

Penambahan lebar jalan yang dilakukan dengan penggeseran material yang menumpuk di badan jalan, bila dilakukan penambahan lebar jalan 5 meter maka sebelah kanan jalan dilebarkan 2,5 meter dan sebelah kiri jalan dilebarkan 2,5 meter. Penambahan lebar jalan untuk jalan lurus dan jalan pada tikungan dapat dilakukan pada saat jam istirahat kerja. Agar tidak mengganggu dump truck yang melintas yang akan menyebabkan menurunnya produksi.

\section{Kemiringan Jalan (Grade)}

Kemiringan jalan berhubungan langsung dengan kemampuan alat angkut, baik untuk pengereman maupun untuk mengatasi tanjakan. Kemiringan jalan produksi di lapangan berkisar antara $3,49 \%$ sampai $15,83 \%$. Kemiringan jalan tersebut masih dapat diatasi oleh alat angkut, 
karena kemampuan dump truck untuk melewati tanjakan adalah $22,46 \%$. Kemiringan jalan terbesar $15,83 \%$ pada segmen $\mathrm{F}$ - G. Karena penurunan grade jalan sulit dilakukan karena akan membutuhkan waktu yang lama dan biaya yang besar, serta mengganggu produksi dan juga masih mampu dilalui oleh dump truck bermuatan, maka disetiap grade yang melebihi $10 \%$ akan dipasang rambu - rambu jalan angkut agar pengemudi dump truck bisa lebih hati - hati. Dan harus dilakukan pemeriksaan berkala terhadap mesin dan ban dump truck agar dalam performa yang baik dalam melewati grade yang melebihi $10 \%$.

\section{Kemiringan Melintang (Cross Slope)}

Kemiringan melintang sangat perlu dibuat untuk mengatasi masalah drainase supaya kondisi permukaan jalan tidak tergenang oleh air dan permukaan jalan tidak mudah rusak sehingga aktifitas pengangkutan batubara menjadi lancar dan produktifitas alat angkut menjadi optimal. Kemiringan melintang saat ini pada jalan produksi yang menghubungkan pit Jebak menuju stockpile berkisar antara $0-52 \mathrm{~mm}$. Sehingga untuk kondisi jalan PT. Nan Riang, jika menggunakan lebar jalan 12 meter kemiringan melintang yang dianjurkan yaitu sebesar $24 \mathrm{~cm}$. Untuk penambahan kemiringan melintang akan dilakukan penimbunan dan pemadatan permukaan jalan, agar didapat beda tinggi dari tepi jalan ke tengah jalan menjadi $24 \mathrm{~cm}$, dan dilanjutkan dengan pembuatan drainase agar air hujan yang masuk ke permukaan jalan langsung mengalir.

\section{Superelevasi}

Tabel 6. Estimasi Income Setelah Perbaikan

\begin{tabular}{|c|c|r|c|r|r|r|}
\hline \multicolumn{2}{|c|}{ Bahan Bakar } & $\begin{array}{c}\text { Biaya Bahan } \\
\text { Bakar (Rp) }\end{array}$ & \multicolumn{2}{c|}{ Produksi Batubara } & \multicolumn{1}{c|}{$\begin{array}{c}\text { Penjualan } \\
\text { Batubara (Rp) }\end{array}$} & Income (Rp) \\
\hline liter/jam & 30.93 & 340,230 & ton/jam & 27.19 & $33,780,992$ & $33,440,762$ \\
\hline liter/hari & 201.05 & $2,211,495$ & ton/hari & 175.92 & $218,563,888$ & $216,352,393$ \\
\hline liter/bulan & 6031.35 & $66,344,850$ & ton/bulan & 5277.60 & $6,556,916,628$ & $6,490,571,778$ \\
\hline 5 dump truck/jam & 154.65 & $1,701,150$ & 5 dump truck /jam & 135.95 & $168,904,960$ & $167,203,810$ \\
\hline 5 dump truck/hari & 1005.23 & $11,057,475$ & 5 dump truck/hari & 879.60 & $1,092,819,438$ & $1,081,761,963$ \\
\hline 5 dump truck/bulan & 30156.75 & $331,724,250$ & 5 dump truck/bulan & 26387.90 & $32,784,458,900$ & $32,452,734,650$ \\
\hline 6 dump truck/jam & 185.58 & $2,041,380$ & 6 dump truck/jam & 163.14 & $202,685,952$ & $200,644,572$ \\
\hline 6 dump truck/hari & 1206.27 & $13,268,970$ & 6 dump truck/hari & 1055.52 & $1,311,383,326$ & $1,298,114,356$ \\
\hline 6 dump truck/bulan & 36188.10 & $398,069,100$ & 6 dump truck/bulan & 31665.47 & $39,341,338,255$ & $38,943,269,155$ \\
\hline
\end{tabular}

\section{KESIMPULAN}

Berdasarkan hasil penelitian yang diperoleh, maka dapat ditarik kesimpulan sebagai berikut

Hubungan pengaruh konsumsi bahan bakar alat angkut UD CWM 330 ketika bermuatan adalah $54 \%$ terhadap kemiringan jalan, 100\% terhadap
Superelevasi ini bertujuan untuk membantu kendaraan dalam mengatasi tikungan. Dengan superelevasi yang ada, diharapkan alat angkut tidak tergelincir pada saat melewati tikungan dengan kecepatan yang maksimum. Secara umum superelevasi yang ada di PT. Nan Riang belum semuanya ada sehingga ketika alat angkut melewati tikungan kecepatan yang dipakai sangat rendah sehingga berpengaruh pada cycle time alat angkut yang semakin besar. Angka superelevasi yang dianjurkan untuk mengatasi tikungan jalan pada PT. Nan Riang dengan kecepatan maksimum $40 \mathrm{~km} / \mathrm{jam}$ dengan lebar jalan ditikungan 21 meter adalah 0,05 . Sehingga beda tinggi antara sisi dalam dan sisi luar tikungan yang harus dibuat 1 meter. Untuk penambahan beda tinggi diluar tikungan akan dilakukan penimbunan dan di lakukan pemadatan agar dump truck dapat melaju dengan kecepatan yang sesuai standar operasional prosedur (SOP) di PT. Nan Riang.

\section{Estimasi Income Perusahaan Setelah Perbaikan}

Jika perusahaan PT. Nan Riang dapat melakukan evaluasi jalan produksi serta perbaikan dengan menekankan waktu hambatan yang dapat dihindari dan penambahan satu unit dump truck UD CWM 330 seperti perkiraan maka produksi 1000 ton/hari akan tercapai, serta penggunaan dan biaya bahan bakar akan dapat dikurangi. Untuk melihat perbandingan estimasi income perusahaan setelah dilakukan perbaikan dapat dilihat pada Tabel 6 . 
64\% terhadap kecepatan, 79\% terhadap rimpull, $3 \%$ terhadap jarak tempuh, dan $1 \%$ terhadap waktu tempuh.

Bahan bakar aktual yang dihabiskan oleh keseluruhan alat angkut dump truck UD CWM 330 sebesar 1.589,52 liter/hari (5 dump truck). Bahan bakar yang dihabiskan oleh keseluruhan alat angkut dump truck UD CWM 330 setelah dilakukan perbaikan sebesar 1.206,27 liter/hari (6 dump truck).

Biaya bahan bakar aktual yang diperlukan oleh keseluruhan alat angkut dump truck UD CWM 330 sebesar Rp17.484.720,-/hari (5 dump truck). Biaya bahan bakar yang diperlukan oleh keseluruhan alat angkut dump truck UD CWM 330 setelah dilakukan perbaikan sebesar Rp13.268.970,-/hari (6 dump truck).

Produksi aktual yang dihasilkan oleh keseluruhan alat angkut dump truck UD CWM 330 sebesar 636,34 ton/hari (5 dump truck). Produksi yang dihasilkan oleh keseluruhan alat angkut dump truck UD CWM 330 setelah dilakukan perbaikan sebesar 1.055,32 ton/hari (6 dump truck).

Adapun beberapa saran yang dapat penulis sampaikan yaitu sebagai berikut:

Dalam melakukan perencaan jalan produksi harus dipertimbangkan faktor kemiringan jalan yang akan dilalui oleh alat angkut karena akan mempengaruhi pemakaian bahan bakar dan produksi alat angkut tersebut.

Peningkatan keahlian dan kesadaran terhadap sikap tepat waktu pada operator alat angkut akan sangat membantu dalam usaha peningkatan produksi.

\section{DAFTAR PUSTAKa}

[1] Aldiyansyah, a. (2016). Analisis Geometri Jalan di Tambang Utara pada PT. Ifishdeco Kecamatan Tinanggea Kabupaten Konawe Selatan Provinsi Sulawesi Tenggara. Jurnal geomine, 4(1).

[2] Aryando, W., Ratminah, W. D., \& Sudarsono, S. (2016). Kajian Teknis Produktivitas Alat Gali Muat dan Alat Angkut pada Pengupasan Tanah Penutup Batubara di Banko Barat PIT 1 PT. Bukit Asam (Persero) TBK UPTE. Jurnal teknologi pertambangan, 1(2).

[3] Asmiani, N., Puspitasari, A., \& Widodo, S. (2017). BIAYA PENAMBANGAN NIKEL PADA PT. BINTANG DELAPAN MINERAL KABUPATEN MOROWALI PROVINSI SULAWESI TENGAH. Jurnal Geomine, 5(2).
[4] Engineering Department PT. Nan Riang

[5] faisal, r., kresno, k., \& poetranto, d. (2016). kajian teknis produksi alat muat dan alat angkut untuk memenuhi target produksi 780.000 ton/bulan di pt semen padang indarung sumatera barat.jurnal teknologi pertambangan, $1(2)$.

[6] Febrianto A. 2016. Kajian Teknis Produksi Alat Gali-Muat Dan Alat Angkut Pada Pengupasan Overburden Di Tambang Batubara PT. Rian Pratama Mandiri Kabupaten Tanah Laut Provinsi Kalimantan Selatan. Jurnal Teknologi Pertambangan Vol. 1, No. 2.

[7] Febrianto, Ardyan. 2016. Kajian Teknis Produksi Alat Gali-Muat dan Alat Angkut Pada Pengupasan Overburden di Tambang Batubara PT. Rian Pratama Mandiri Kabupaten Tanah Laut Provinsi Kalimantan Selatan. Jurnal Teknologi Pertambangan Vol. 1, No. 2.

[8] Genta Dwi. 2016. Kajian Teknis Produksi Alat Gali-Muat Dan Alat Angkut Untuk Memenuhi Target Produksi Pengupasan Overburden Penambangan Batubara Pt. Citra Tobindo Sukses Perkasa Kabupaten Sarolangun Provinsi Jambi. Jurnal Teknologi Pertambangan Vol. 1, No. 2.

[9] Putri, M., Yulhendra, D., \& Octova, A. (2018). Optimasi Geometri Peledakan Untuk Mencapai Target Fragmentasi Dan Diggability Dalam Pemenuhan Target Produktivitas Ore Di Pit Durian Barat Dan Pit South Osela Site Bakan Pt J Resources Bolaang Mongondow Sulawesi Utara. Bina Tambang, 3(1), 588-607.

[10] Murnawan, H. (2016). Perencanaan Produktivitas Kerja Dari Hasil Evaluasi Produktivitas Dengan Metode Fishbone Di Perusahaan Percetakan Kemasan Pt. X. HEURISTIC: Jurnal Teknik Industri, 11(01).

[11] Octova, A., \& Yulhendra, D. (2017). Iron ore deposits model using geoelectrical resistivity method with dipole-dipole array. In MATEC Web of Conferences (Vol. 101, p. 04017). EDP Sciences.

[12] Octova, A., \& Sule, R. (2018, April). Seismic Travel Time Tomography in Modeling Low Velocity Anomalies between the Boreholes. In IOP Conference Series: Materials Science and Engineering (Vol. 335, No. 1, p. 012056). IOP Publishing.

[13] Sari, R. P., Murad, M., \& Octova, A. (2018). Analisis Statistik Untuk Mendapatkan Waktu Optimal Dari Losstime Dalam Memenuhi 
Produksi Penambangan Batubara Di Area Pit Timur PT. Artamulia Tatapratama. Bina Tambang, 3(3), 943-952.

[14] Shaddad, A. R. (2017). ANALISIS KESERASIAN ALAT MEKANIS (MATCH FACTOR) UNTUK PENINGKATAN PRODUKTIVITAS. Jurnal Geomine, 4(3).

\section{Biodata Penulis}

Adree Octova, lahir di Padang Pariaman, 28 Oktober 1986. Sarjana Fisika dari Universitas Negeri Padang, lulus 2008. Tahun 2011 memperoleh gelar Magister Teknik Geofisika dari Institut Teknologi Bandung

Raka Tubagus Indra Ramadhan, lahir di Padang, 3 Februari 1995. Menyelesaikan studi S1 di Jurusan Teknik Pertambangan Fakultas Teknik Universitas Negeri Padang 